\title{
Admission blood glucose and 10-year mortality among patients with or without pre-existing diabetes mellitus hospitalized with heart failure
}

Osnat Itzhaki Ben Zadok ${ }^{1,4}$, Ran Kornowski 1,4, llan Goldenberg 2,4, Robert Klempfner ${ }^{2,4}$, Yoel Toledano ${ }^{3,4}$, Yitschak Biton ${ }^{2,4}$, Enrique Z. Fisman ${ }^{2,4}$, Alexander Tenenbaum ${ }^{2,4}$, Gregory Golovchiner ${ }^{1,4}$, Ehud Kadmon ${ }^{1,4}$, Alexander Omelchenko ${ }^{1}$, Tuvia Ben Gal ${ }^{1,4}$ and Alon Barsheshet ${ }^{1,4^{*}}$ (D)

\begin{abstract}
Background: High admission blood glucose (ABG) level has been associated with a poor short-term outcome among non-diabetic patients with heart failure (HF). We aimed to investigate the association between ABG levels and long-term (10 years) mortality in patients with or without pre-existing diabetes mellitus (DM) admitted with HF.

Methods: We analyzed data on 1811 patients with DM and 2182 patients without pre-existing DM who were hospitalized with HF during a prospective national survey. The relationship between ABG and 10-year mortality was assessed using the Cox proportional hazard model adjusting for multiple variables. ABG was analyzed both as a categorical $(<110,110-140,140-200$, and $>200 \mathrm{mg} / \mathrm{dL})$ and as a continuous variable.

Results: At 10 years of follow-up the cumulative probability of mortality was 85 and $78 \%$ among patients with DM and patients with no pre-existing DM $(p<0.001)$, respectively. Among patients with no pre-existing DM, glucose levels of $110-140,140-200$ and $\geq 200 \mathrm{mg} / \mathrm{dL}$ were associated with $9 \%(p=0.140), 16 \%(p=0.031)$ and $53 \%(p<0.001)$ increased mortality risk compared to $A B G<110 \mathrm{mg} / \mathrm{dL}$. Each $18-\mathrm{mg} / \mathrm{dL}(1-\mathrm{mmol} / \mathrm{L})$ increase in glucose level was associated with a $5 \%$ increased risk of mortality $(p<0.001)$ among patients with no-pre-existing DM. In contrast, among patients with DM, only those with glucose levels $>200 \mathrm{mg} / \mathrm{dL}$ had an increased mortality risk ( $>200 \mathrm{mg} / \mathrm{dL}$ versus $<110 \mathrm{mg} / \mathrm{dL} ; \mathrm{HR}=1.20, \mathrm{p}=0.032$ ).

Conclusion: Among hospitalized HF patients with no pre-existing DM there is a linear relationship between ABG level and long-term mortality, whereas among patients with DM only ABG level $>200 \mathrm{mg} / \mathrm{dL}$ is associated with increased mortality risk.
\end{abstract}

Keywords: Heart failure, Diabetes mellitus, Prognosis, Admission blood glucose

\section{Background}

Patients admitted with heart failure (HF) carry a poor long-term prognosis with an estimated 50 percent mortality rate at 5 years of follow-up [1]. Diabetes mellitus (DM) is a major contributor to the development of HF

\footnotetext{
*Correspondence: barshesheta@gmail.com

${ }^{1}$ Department of Cardiology, Rabin Medical Center, 39 Jabotinski St., Petah Tikva, Israel

Full list of author information is available at the end of the article
}

and its associated poor prognosis [2-6]. Several studies have shown that admission blood glucose (ABG) levels are correlated with short-term prognosis in the acute HF setting both in patients with DM and in patients without DM [7-13]; nevertheless, others have shown no correlation between ABG levels and short-term mortality among patients with acute HF $[14,15]$. Furthermore, data on the association between ABG levels and long-term mortality among HF patients is scarce $[11,13,16]$. 
The current study was designed to investigate the association between ABG levels and long-term mortality (10 years) in hospitalized HF patients with DM and without pre-existing DM included in the Heart Failure survey in Israel (HFSIS). Since plasma glucose is an easily measured, inexpensive laboratory test and a potentially modifiable risk factor, ABG levels may have important clinical implications for risk stratification and treatment of patients admitted with HF.

\section{Methods}

\section{Study population and data collection}

Baseline and admission characteristics of patients were extracted from the Heart Failure Survey in Israel (HFSIS) 2003 database as previously described [17]. Briefly, this survey, conducted through March and April 2003, included 4102 patients with a diagnosis of either acute de-novo HF, acute exacerbation of chronic HF, or chronic HF, who were admitted to one of the 25 public hospitals operating in Israel. The criteria used for the diagnosis of HF were symptoms of HF (at rest or during exertion) and objective evidence of cardiac dysfunction at rest [18]. Diagnosis of acute HF or exacerbation of chronic HF was determined by the attending physician based on history, symptoms and physical examination, response to HF therapy, chest radiography, echocardiography, radionuclide studies, cardiac catheterization findings and in-hospital course. Detailed data regarding patient characteristics, in-hospital course and management, prehospital and discharge medications and diagnoses were collected and recorded by physicians on pre-specified structured forms. The study was conducted in accordance with the International Conference on Harmonization Guidelines for Good Clinical Practice and the Declaration of Helsinki. The ethics committee at each of the participating hospitals approved the protocol.

We have excluded patients with ABG levels below $70 \mathrm{mg} / \mathrm{dL}(3.9 \mathrm{mmol} / \mathrm{L})$ or above $600 \mathrm{mg} / \mathrm{dL}(33 \mathrm{mmol} / \mathrm{L})$ as previously done [7] to ensure a homogenous study population and avoid including patients with possible errors, patients with hypoglycemia or severe hyperosmolar hyperglycemia. Thus, our final analysis included 3993 patients of whom 2182 presented with no preexisting DM and 1811 presented as patients with DM based on either a history of DM obtained from medical records or the use of anti-diabetic agents on admission. Patients were then sub-divided based on their ABG level similar to previously described thresholds $[7,14,19]$ : glucose $<110 \mathrm{mg} / \mathrm{dL}(6.1 \mathrm{mmol} / \mathrm{L}), 110-140 \mathrm{mg} / \mathrm{dL}(6.1-$ $7.8 \mathrm{mmol} / \mathrm{L}), 140-200 \mathrm{md} / \mathrm{dL}(7.8-11.1 \mathrm{mmol} / \mathrm{L})$ and above $200 \mathrm{mg} / \mathrm{dL}(11.1 \mathrm{mmol} / \mathrm{L})$.

ABG levels were determined as the first blood glucose test on the day of admission as reported in the medical records. Left ventricular ejection fraction (LVEF) was determined by echocardiography. The LVEF data were collected by medical chart review and recorded only if echocardiography was performed within 1 year prior to or during hospitalization. Out of the 3993 study patients, 2775 had LVEF data. Echocardiography was performed in 1536 patients during index hospitalization. LVEF classes were classified as follows: normal $-\geq 50 \%$; mildly impaired-40 to $49 \%$; moderately impaired-30 to $39 \%$; severely impaired $\leq 30 \%$. The median (interquartile range [Q1-Q3]) timing of echocardiography was 0 month (0-6 months) prior to index admission.

\section{Outcome measures}

The end point of this study was all-cause mortality. During the 10 years after index hospitalization, mortality was assessed for all patients by matching their identification numbers with the Israeli National Population Registry.

\section{Statistical analysis}

Continuous variables were expressed as median (interquartile range). Baseline characteristics of the groups (continuous data) were compared by use of the nonparametric Kruskal-Wallis test; categorical variables and frequencies were compared by means of the $x^{2}$ test. Kaplan-Meier survival curves were produced and compared using the log-rank test. To examine the relationship between ABG level and mortality several models were conducted. First, potential variables (identified in previously published studies $[20,21]$ as risk factors for mortality) were evaluated by univariate analysis and were selected based on clinical and statistical significance. The values used to dichotomize the variables were taken from previous reports [20, 21]. Second, multi-variable Cox proportional hazards regression analysis was used to assess the independent association between ABG levels and the risk of all-cause mortality. Covariates included in the multivariate models were identified using a best subset procedure, choosing among a wide variety of available baseline measures with the additional stipulation that they needed to be statistically significant with an individual $\mathrm{p}$ value $<0.05$ for inclusion. Thus, all models were adjusted for ABG (analyzed as a categorical variable and as a continuous variable in separate models), age, chronic obstructive pulmonary disease, active malignancy, urea, creatinine, NYHA functional class III and IV versus I and II, acute de novo or acute exacerbation of chronic HF, systolic blood pressure $<115$ or $\geq 115 \mathrm{mmHg}$, [21] hemoglobin, and the following pre-hospital medication use: statins, $\beta$-blockers and furosemide. Gender was also forced into the model. In the subgroup of patients with DM we have repeated the multivariable analysis including also oral hypoglycemic drugs and insulin as covariates. 
Finally, the same multivariable models for 10 -year mortality were adjusted for all of the above parameters plus LVEF class for 2775 patients with LVEF data. All statistical tests were two-sided and a $\mathrm{p}$ value $<0.05$ was considered statistically significant. Analyses were carried out with SAS software version 9.4 (SAS Institute, Cary, North Carolina).

\section{Results}

\section{Patient characteristics}

We identified 2182 patients with no pre-existing DM and 1811 with DM. Patients were sub-divided based on their ABG levels similar to previously described thresholds (Table 1) $[7,14,19]$. The mean follow-up duration was 4.2 years. Patients with DM were younger and more likely to have a history of hypertension, dyslipidemia, ischemic heart disease, stroke and PVD as compared with patients with no pre-existing DM. Patients with no pre-existing DM were more likely to have a history of atrial fibrillation. As for chronic medication use reported on admission-aspirin, statins, beta-blockers, angiotensin converting enzyme inhibitors (ACEIs) or angiotensin receptor blockers (ARBs), furosemide and thiazides were more frequently used in the DM group. Out of 1811 DM patients, 375 patients were treated with insulin and 1013 were treated with oral hypoglycemic medications. The median ABG level was $114 \mathrm{mg} / \mathrm{dL}$ (interquartile range 98-140) and $182 \mathrm{mg} / \mathrm{dL}$ (interquartile range 134-255) for the subgroups of patients with no pre-existing DM and those with known DM, respectively $(\mathrm{p}<0.001)$. Hemoglobin and GFR levels were lower in the DM group.

Of note, in the subgroup of patients with no pre-existing DM, elevated ABG levels were associated with higher proportion of females, increased rates of myocardial infarction at presentation, poorer renal function, lower sodium levels and faster heart rates on admission.

\section{Diabetes mellitus and long term mortality}

The cumulative probabilities of death over 10 years of follow-up in patients with DM versus patients with no pre-existing DM are presented in Fig. 1. By multivariate analysis, patients with DM had a 1.3-fold increased risk of mortality (95\% confidence interval 1.22-1.41, $\mathrm{p}<0.001)$.

\section{ABG and mortality among patients with no pre-existing diabetes mellitus}

Among patients with no pre-existing DM the 10-year mortality risk correlated with ABG levels (Fig. 2). Thus, at 10 years of follow-up the cumulative probability of death was $76 \%$ for patients with $A B G<110 \mathrm{mg} / \mathrm{dL}, 78 \%$ for patients with ABG $110-140 \mathrm{mg} / \mathrm{dL}, 80 \%$ for patients with $140-200 \mathrm{mg} / \mathrm{dL}$ and $90 \%$ for patients with ABG $\geq 200 \mathrm{mg} / \mathrm{dL}$ ( $\mathrm{p}<0.001$ for the overall comparison).

Consistently, multivariate analysis (Table 2) demonstrated that high ABG levels were associated with an increment risk of death. Patients with ABG levels of $110-140,140-200$ and $\geq 200 \mathrm{mg} / \mathrm{dL}$ had a respective 9\% ( $\mathrm{p}=0.140), 16 \%(\mathrm{p}=0.031)$, and 53\% $(\mathrm{p}<0.001)$ increased mortality risk compared to patients with ABG $<110 \mathrm{mg} / \mathrm{dL}$. Also, the results were consistent when further adjusted for LVEF class (among patients who had LVEF data). In a separate multivariable model (Table 2), each $18-\mathrm{mg} / \mathrm{dL}(1-\mathrm{mmol} / \mathrm{L})$ increase in glucose level was associated with a $5 \%$ increased risk of mortality $(\mathrm{p}<0.001)$; notably, ABG measured as a continuous variable remained an independent predictor of mortality also after excluding patients with ABG levels $>200 \mathrm{mg} / \mathrm{dL}$ $(\mathrm{HR}=1.04$ per $18 \mathrm{mg} / \mathrm{dL}$ increase in $\mathrm{ABG}, \mathrm{p}=0.014)$. In a secondary analysis adjusting also for IHD, MI at presentation, antiplatelet agents and thiazides, results remained the same. In addition, results remained the same when patients with acute MI at presentation were excluded from the analysis. There was no significant interaction between ABG and acute or chronic HF status (ABG-byacute $\mathrm{HF} \mathrm{p}$ for interaction $=0.837)$ and there was no significant interaction between ABG and age (ABG-by-age $\geq 75 \mathrm{p}$ value for interaction $=0.277$ ), implying that the relationship between high ABG levels and mortality does not change according to acute or chronic HF status or in the different age groups.

\section{ABG and mortality among patients with diabetes mellitus}

Among patients with known DM, Kaplan-Meier survival curves showed that there were no significant differences in mortality risk between the ABG subgroups $(\mathrm{p}=0.138$, Fig. 3). Likewise, multivariable analysis (Table 3) demonstrated that there were no significant differences in mortality risk when patients with ABG levels $110-140 \mathrm{mg} /$ $\mathrm{dL}(\mathrm{HR}=0.91, \mathrm{p}=0.35)$ or $\mathrm{ABG} 140-200 \mathrm{mg} / \mathrm{dL}$ $(\mathrm{HR}=1.08, \mathrm{p}=0.38)$ were compared to patients with ABG $<110 \mathrm{mg} / \mathrm{dL}$. An exception was noted in the ABG $>200 \mathrm{mg} / \mathrm{dL}$ subgroup experiencing a 1.2 -fold increased risk of death $(95 \% \mathrm{CI} 1.01-1.42, \mathrm{p}=0.032)$ compared to patients with $A B G<110 \mathrm{mg} / \mathrm{dL}$. When adding oral hypoglycemic medications and insulin to the multivariable analyses, results were consistent showing that among patients with DM only those with ABG $>200 \mathrm{mg} / \mathrm{dL}$ were associated with increased mortality risk $(>200 \mathrm{mg} /$ $\mathrm{dL}$ versus $<110 \mathrm{mg} / \mathrm{dL} H R=1.20, \mathrm{p}=0.04$ ). Adjusted analysis of continuous glucose showed that each $18-\mathrm{mg} /$ $\mathrm{dL}(1-\mathrm{mmol} / \mathrm{L})$ increase in glucose level was associated with a $2 \%$ increased risk of mortality $(\mathrm{p}<0.001)$; this result was mainly driven by the effect of ABG $>200 \mathrm{mg} /$ $\mathrm{dL}$ as this relationship was statistically insignificant when 
Table 1 Patient characteristics in the DM group and the no pre-existing DM Group (categorized by quartiles of ABG levels)

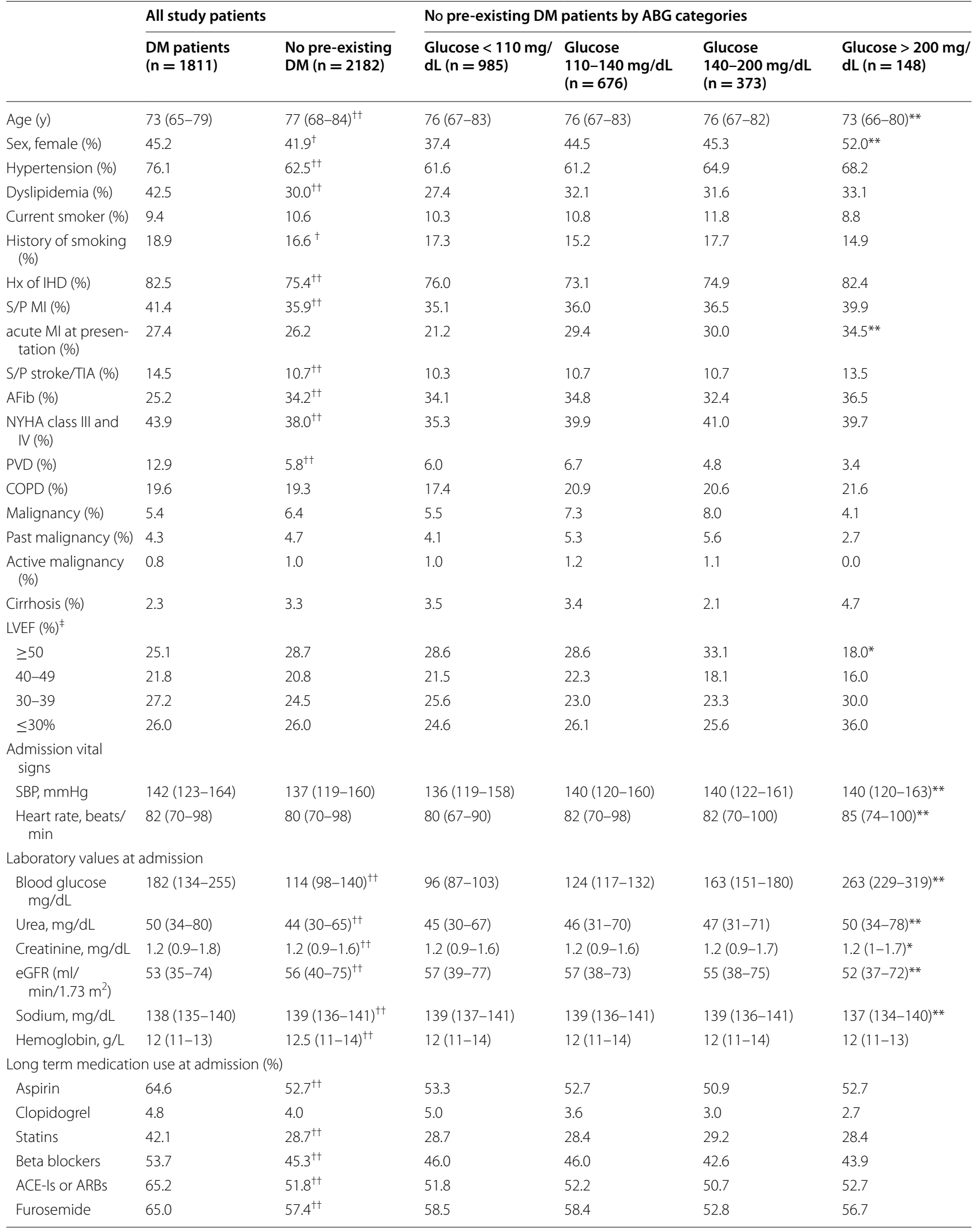


Table 1 continued

\begin{tabular}{|c|c|c|c|c|c|c|}
\hline & \multicolumn{2}{|c|}{ All study patients } & \multicolumn{4}{|c|}{ No pre-existing DM patients by $A B G$ categories } \\
\hline & $\begin{array}{l}\text { DM patients } \\
(n=1811)\end{array}$ & $\begin{array}{l}\text { No pre-existing } \\
\text { DM }(n=2182)\end{array}$ & $\begin{array}{l}\text { Glucose }<110 \mathrm{mg} / \\
\mathrm{dL}(\mathrm{n}=985)\end{array}$ & $\begin{array}{l}\text { Glucose } \\
110-140 \mathrm{mg} / \mathrm{dL} \\
(\mathrm{n}=676)\end{array}$ & $\begin{array}{l}\text { Glucose } \\
140-200 \mathrm{mg} / \mathrm{dL} \\
(\mathrm{n}=373)\end{array}$ & $\begin{array}{l}\text { Glucose }>200 \mathrm{mg} / \\
\mathrm{dL}(\mathrm{n}=148)\end{array}$ \\
\hline Thiazide & 7.45 & $5^{t+}$ & 4.0 & 5.9 & 6.4 & 4.0 \\
\hline Spironolactone & 15.1 & 13.6 & 14.5 & 12.9 & 12.6 & 13.5 \\
\hline
\end{tabular}

Data are given as median (interquartile range) or percentage unless otherwise indicated

SI conversion factors: To convert glucose to millimoles per liter, multiply by 0.055 ; to convert urea to millimoles per liter, multiply by 0.357 ; to convert creatinine to micromoles per liter, multiply by 88.4

$A B G$ admission blood glucose, $A C E-l$ angiotensin-converting enzyme inhibitor, $A R B$ angiotensin receptor blocker, $C O P D$ chronic obstructive pulmonary disease, $D M$ diabetes mellitus, LVEF left ventricular ejection fraction, $M I$ myocardial infarction, NA not applicable, NYHA New York Heart Association, PVD peripheral vascular disease, SBP systolic blood pressure, $S / P$ status post, TIA transient ischemic attack

${ }^{*} p<0.1$ and ** $p<0.01$ for trend among quartiles of ABG levels in patients with no pre-existing DM

${ }^{\dagger} \mathrm{p}<0.1$ and ${ }^{\dagger \dagger} \mathrm{p}$ value $<0.01$ for comparison between patients with DM and patients with no pre-exisiting DM

₹ Of 3993 patients, 2775 had LVEF data

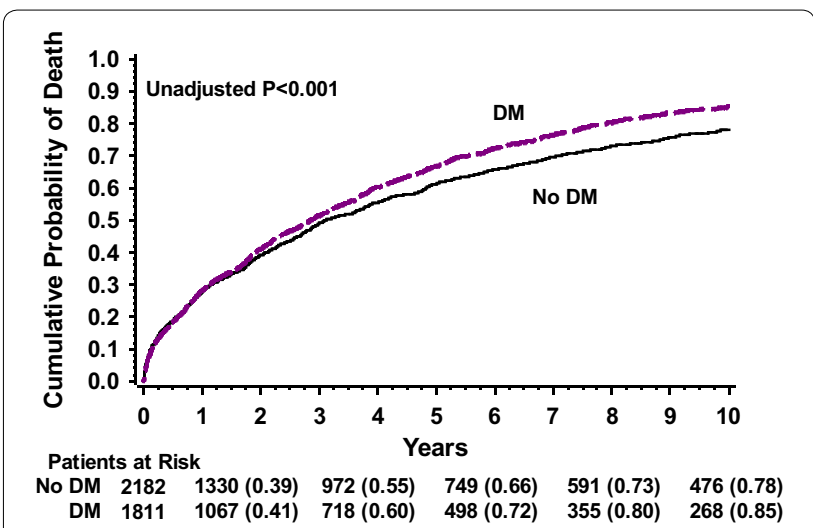

Fig. 1 Kaplan-Meier estimates of probability of death in patients with DM versus patients with no pre-existing DM. DM diabetes mellitus

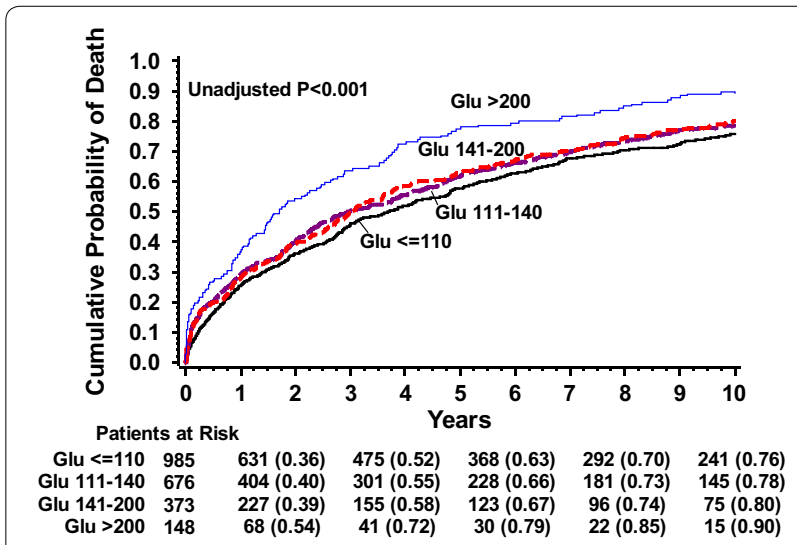

Fig. 2 Kaplan-Meier estimates of probability of death in patients with no pre-existing DM according to $A B G$ level subgroups. $A B G$ admission blood glucose, DM diabetes mellitus

patients with $A B G>200 \mathrm{mg} / \mathrm{dL}$ were excluded from the analysis $(\mathrm{p}=0.283)$.

\section{Discussion}

The current study provides two important findings among hospitalized patients with HF. First, ABG level is an independent predictor of long-term (10-year) mortality among patients with no pre-existing DM. Second, among patients with DM only very high ABG levels ( $>200 \mathrm{mg} / \mathrm{dL}$ ) predict worse outcome.

The epidemiological association between DM and HF has been firmly established by the Framingham Study [2], which showed a 2.4- and 5-fold increase in the risk of HF in men and women with DM, respectively. Similar findings have been published by others $[5,6,22]$. This may be due to both the presence of co-morbidities associated with DM and to the development of a distinct entity of diabetic cardiomyopathy [23-25]. Functionally, diabetic cardiomyopathy is characterized by increased myocardial fibrosis, higher LV mass and wall thickness leading to both systolic and diastolic dysfunction; the latter is present even before the clinical onset of diabetes, reflecting mainly an increased insulin resistance [26, 27].

Moreover, it has been postulated that HF by itself, and especially in patients with decreased functional capacity, predisposes patients to the development of $\operatorname{DM}[5,7,28$, 29].

The strong association between DM and mortality has been demonstrated repeatedly in patients with HF [2-6]. Our results agree with those findings showing a 1.3-fold increased mortality risk in DM patients admitted with HF compared with patients with no pre-existing DM. Furthermore, the association between ABG levels and mortality has also been established in different clinical settings such as in patients with acute coronary syndrome [19, 30-33] and acute cerebrovascular ischemia [34-36]. However, there is a debate whether ABG levels are associated with increased mortality among patients with HF. Studies published so far have mostly focused on 
Table 2 Admission blood glucose levels and mortality among patients with no pre-existing DM by multivariate analysis

\begin{tabular}{|c|c|c|c|c|}
\hline & & & $\mathrm{HR}(95 \% \mathrm{Cl})^{\dagger}$ & $p^{\dagger}$ \\
\hline \multirow[t]{6}{*}{ ABG level category* } & \multirow[t]{3}{*}{ Not adjusted to \%LVEF } & $110-140 \mathrm{mg} / \mathrm{dL}$ & $1.09(0.97-1.22)$ & 0.140 \\
\hline & & $140-200 \mathrm{mg} / \mathrm{dL}$ & $1.16(1.01-1.33)$ & 0.031 \\
\hline & & $>200 \mathrm{mg} / \mathrm{dL}$ & $1.53(1.26-1.85)$ & $<0.001$ \\
\hline & \multirow[t]{3}{*}{ Adjusted to \%LVEF } & $110-140 \mathrm{mg} / \mathrm{dL}$ & $1.03(0.89-1.19)$ & 0.682 \\
\hline & & $140-200 \mathrm{mg} / \mathrm{dL}$ & $1.26(1.06-1.48)$ & $<0.001$ \\
\hline & & $>200 \mathrm{mg} / \mathrm{dL}$ & $1.50(1.18-1.90)$ & $<0.001$ \\
\hline \multirow[t]{3}{*}{ Per $18 \mathrm{mg} / \mathrm{dL}$ glucose $(1 \mathrm{mmol} / \mathrm{L})^{*}$} & Not adjusted to \%LVEF & & $1.05(1.03-1.08)$ & $<0.001$ \\
\hline & Adjusted to \%LVEF ${ }^{\ddagger}$ & & $1.05(1.03-1.08)$ & $<0.001$ \\
\hline & Patients with $A B G$ level $<200 \mathrm{mg} / \mathrm{dL}$ only & & $1.04(1.01-1.08)$ & 0.014 \\
\hline
\end{tabular}

To convert glucose to millimoles per liter, multiply by 0.055

$A B G$ admission blood glucose, $C l$ confidence interval, $D M$ diabetes mellitus, $H R$ hazard ratio, $L V E F$ left ventricular ejection fraction

* Adjusted for age, sex, COPD, NYHA 3,4, acute on chronic and chronic HF categories, statins, beta-blockers, furosemide, active malignancy, hemoglobin, urea, creatinine, SBP

† HR and p-value compared to ABG $<110 \mathrm{mg} / \mathrm{dL}$

₹ Of 3993 patients, 2775 had LVEF data

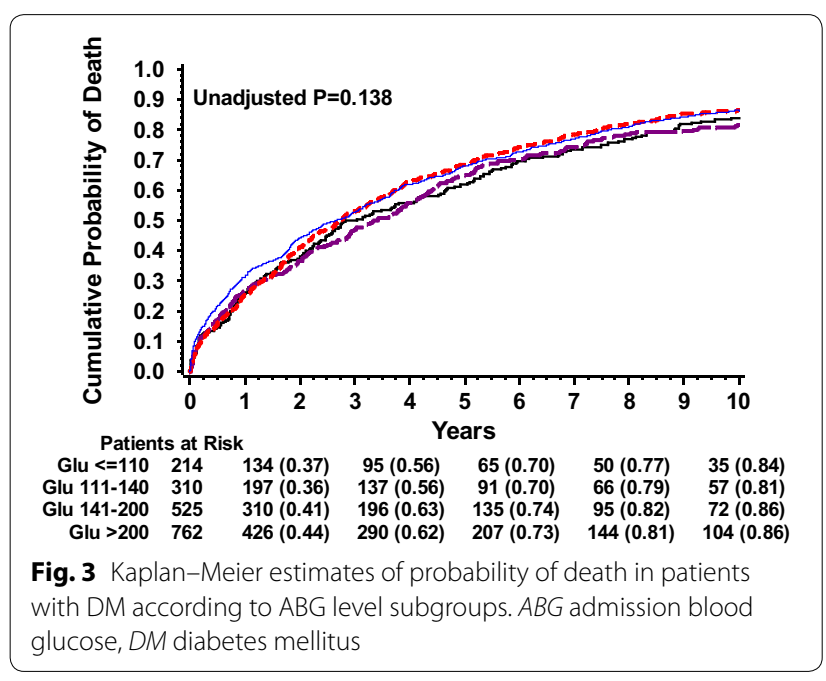

the correlation between ABG levels and short-term or mid-term mortality (mostly up to 1 year of follow-up). In their study, Sud et al. [7] included patients who presented to the emergency room with acute HF. The 30-day allcause mortality was elevated among patients with no preexisting DM who presented with ABG levels higher than $110 \mathrm{mg} / \mathrm{dl}$. These results are in concordance with previous reports by others $[8-10,12,13]$ who have also demonstrated increased 30-day mortality in HF patients with elevated ABG levels. Nevertheless, several investigators have shown opposite results: Kosiborod et al. have investigated the correlation between ABG levels and mortality in a large cohort of elderly Medicare beneficiaries in the USA [14]. Also, in a retrospective population-based study Novack et al. [15] have evaluated the relationship between routine ABG levels of patients admitted for decompensated HF and prognosis. Both studies did not demonstrate a correlation between ABG levels and 30-day or 1-year mortality. In a recently published report from the prospective European Society of Cardiology Heart Failure Long-Term Registry (ESC-HF-LT) [12] an elevated ABG level was not associated with an increased 1 -year mortality both in patients with or without DM. Furthermore, in a report from the PROTECT study [35] an elevated ABG level was associated with a slightly better outcome in 180 days of follow-up.

The present study is among the first ones to characterize the relationship between ABG and long-term (10year) mortality in patients admitted with $\mathrm{HF}$ and to show a direct correlation between ABG levels and long-term mortality in patients with no pre-existing DM. We have previously shown [10] that patients with no pre-existing DM admitted with acute HF exhibit an increased inhospital and 60-day mortality associated with elevated ABG levels; the current study extends these findings to 10 years of follow up. Herein, we included both acute and chronic HF patients and showed that each $18 \mathrm{mg} / \mathrm{dL}$ $(1 \mathrm{mmol} / \mathrm{L})$ increase in ABG level was associated with an adjusted $5 \%$ increased risk of mortality $(\mathrm{p}<0.001)$ among patients with no pre-existing DM. By contrast, among patients with DM, only those with ABG levels $\geq 200 \mathrm{mg}$ / $\mathrm{dL}$ had an increased mortality risk $(>200 \mathrm{mg} / \mathrm{dL}$ versus $<110 \mathrm{mg} / \mathrm{dL}, \mathrm{HR}=1.20, \mathrm{p}=0.032$ ). Similarly, Newton et al. [13] investigating the relationship between ABG and mortality among 479 hospitalized HF patients during a mean follow-up of 3.4 years, found that ABG greater than $180 \mathrm{mg} / \mathrm{dL}$ in patients with no pre-existing DM was 
Table 3 Admission blood glucose and mortality among DM patients by multivariate analysis

\begin{tabular}{|c|c|c|c|c|}
\hline & & & $\mathrm{HR}(95 \% \mathrm{Cl})^{\dagger}$ & $p^{\dagger}$ \\
\hline \multirow[t]{6}{*}{ ABG level category* } & Not adjusted to \%LVEF & $110-140 \mathrm{mg} / \mathrm{dL}$ & $0.91(0.75-1.10)$ & 0.347 \\
\hline & & $140-200 \mathrm{mg} / \mathrm{dL}$ & $1.08(0.90-1.29)$ & 0.380 \\
\hline & & $>200 \mathrm{mg} / \mathrm{dL}$ & $1.20(1.01-1.42)$ & 0.032 \\
\hline & Adjusted to \%LVEF ${ }^{\ddagger}$ & $110-140 \mathrm{mg} / \mathrm{dL}$ & $1.05(0.83-1.33)$ & 0.665 \\
\hline & & $140-200 \mathrm{mg} / \mathrm{dL}$ & $1.20(0.97-1.48)$ & 0.091 \\
\hline & & $>200 \mathrm{mg} / \mathrm{dL}$ & $1.36(1.12-1.66)$ & 0.002 \\
\hline \multirow[t]{3}{*}{ Per $18 \mathrm{mg} / \mathrm{dL}$ glucose $(1 \mathrm{mmol} / \mathrm{L})^{*}$} & Not adjusted to \%LVEF & & $1.02(1.01-1.03)$ & $<0.001$ \\
\hline & Adjusted to \%LVEF & & $1.02(1.01-1.04)$ & $<0.001$ \\
\hline & Patients with $A B G$ level $<200 \mathrm{mg} / \mathrm{dL}$ only & & $1.02(0.98-1.06)$ & 0.283 \\
\hline
\end{tabular}

To convert glucose to millimoles per liter, multiply by 0.055

$A B G$ admission blood glucose, $C l$ confidence interval, $D M$ diabetes mellitus, $H R$ hazard ratio, $L V E F$ left ventricular ejection fraction

* Adjusted for age, sex, COPD, NYHA 3,4, acute on chronic and chronic HF categories, statins, beta-blockers, furosemide, active malignancy, hemoglobin, urea, creatinine, SBP

+ HR and $\mathrm{p}$-value compared to $A B G<110 \mathrm{mg} / \mathrm{dL}$

* Of 3993 patients, 2775 had LVEF data

a predictor of death, but in patients with DM the level of ABG did not predict mortality.

It is unclear whether high ABG level in HF patients is a marker or a mediator for adverse cardiovascular outcome. As simply a marker for high-risk patients, elevated ABG levels could signify an excess stress response mediated by neuro-hormonal system activation, specifically cortisol and catecholamines [37]. Furthermore, impaired myocardial performance (such as in HF patients) results in the activation of compensatory neuro-hormonal systems, including activation of the sympathetic nervous system [38, 39]. This in turn increases insulin resistance and at the same time stimulates both gluconeogenesis and glycogenolysis [40, 41]. Alternatively, hyperglycemia per-se may mediate the cascade of HF by several independent mechanisms. First, hyperglycemia promotes anaerobic myocardial metabolism, inhibits production of nitric oxide and increases the production of reactive oxygen species in endothelial and vascular smooth muscle cells, thus impairing endothelial function $[42,43]$. Second, hyperglycemia alters cardiac structure through posttranslational modification of extracellular matrix, both leading to impaired relaxation and increased ventricular stiffness and alters calcium metabolism [44-48]. Finally, insulin deficiency is associated with increased lipolysis and excess circulating free fatty acids, which are toxic to ischemic myocardium and were shown to be associated with the development of arrhythmias [49]. In this context, it should be remembered that HF in diabetic patients has specific biomarkers, different than in their non-diabetic counterparts; only in the former hs-troponin $\mathrm{T}$ and the IL1 receptor ST2 are independently associated with both all-cause and cardiovascular outcomes [50, 51].
In contrast to the linear relationship between $A B G$ level and 10-year mortality among patients with no pre-existing DM, we show here that there were no significant differences in the cumulative mortality rates among the ABG subgroups in patients with DM, except for increased mortality risk observed in the multivariate analysis model in patients with very high ABG levels $(>200 \mathrm{mg} / \mathrm{dL})$. There are few possible explanations for this unequivocal correlation between ABG level and long-term mortality in patients with DM: As most of DM patients are treated with glucose-lowering medications it is possible that anti-hyperglycemic treatment may obscure the relationship between ABG and clinical outcome at moderate-high $\mathrm{ABG}$ levels, but not at very high ABG levels. Alternatively, it is possible that ABG level is a less sensitive marker of activation of the sympathetic nervous system and other neuro-hormonal systems among patients with known DM who already have a significant microvascular or macrovascular disease.

\section{Study limitations}

Study results can be influenced by differences in disease assessment and documentation patterns at participating hospitals. We do not have data on hemoglobin A1C levels or long term DM status and therefore are unable to comment on the differential impact of acutely versus chronically elevated blood glucose levels. As a result, it is conceivable that some patients with DM may have been classified as no pre-existing DM patients. Furthermore, we have no information regarding medication changes and clinical events following hospital discharge. Also, we do not have data on acute stress markers nor on neurohormone levels and are not able to establish a casual 
relationship between elevated ABG levels and mortality. Notwithstanding, the powerful association between elevated glucose levels and mortality is important and implies the need for further study.

\section{Conclusions}

In the present study we have shown that ABG level is a strong independent predictor of long-term 10-year mortality in hospitalized HF patients with no pre-existing DM. Whereas, only very high levels of ABG (>200 mg/ $\mathrm{dL}$ ) were associated with increased long-term mortality among patients with DM. Measurement of an ABG level, an available and inexpensive blood test, in patients admitted with HF may help clinicians detect a subgroup of patients that carry a poorer long-term prognosis. These patients should be monitored more closely and treated more intensively. It is possible that better glucose control may improve prognosis in HF patients as previously suggested in critically ill patients [32, 52, 53]. Further research is needed to determine whether hyperglycemia is a marker or a cause of adverse outcome and whether glycemic control would improve short and long term survival in this high risk HF group of patients.

\section{Abbreviations \\ ABG: admission blood glucose; ACEi: angiotensin converting enzyme inhibi- tor; ARBi: angiotensin receptor blocker inhibitor; CKD: chronic kidney disease; COPD: chronic obstructive pulmonary disease; DM: diabetes mellitus; HF: heart failure; LVEF: left ventricular ejection fraction; MI: myocardial infarction; NYHA New York Heart Association. \\ Authors' contributions \\ $A B$ wrote the manuscript and performed statistical analyses. Ol wrote the paper. RK, IG, RK, YT, YB, EZF, AT, GG, EK, AO, TBG reviewed and edited the manuscript. All authors read and approved the final manuscript.}

\section{Author details}

${ }^{1}$ Department of Cardiology, Rabin Medical Center, 39 Jabotinski St., Petah Tikva, Israel. 2"Leviev" Heart Center, Sheba Medical Center, Tel Hashomer, Ramat Gan, Israel. ${ }^{3}$ Division of Maternal-Fetal Medicine, Helen Schneider Hospital for Women, Rabin Medical Center, Petah Tikva, Israel. ${ }^{4}$ Sackler Faculty of Medicine, Tel Aviv University, Tel Aviv, Israel.

\section{Acknowledgements}

We thank all the physicians and nurses at the participating hospitals for their help during the course of the study.

\section{Competing interests}

Alexander Tenenbaum and Enrique Z. Fisman-Editors-in-Chief of Cardiovascular Diabetology, rest of the authors declare that they have no competing interests.

\section{Availability of data and materials}

The datasets during and/or analyzed during the current study are available from the corresponding author on reasonable request.

\section{Ethics approval and consent to participate}

The study was conducted in accordance with the International Conference on Harmonization Guidelines for Good Clinical Practice and the Declaration of Helsinki. The ethics committee at each of the participating hospitals approved the protocol.

\section{Funding}

The Heart Failure Survey in Israel (HFSIS) 2003 was supported by the Israel Center for Disease Control; the Israel Medical Association; and Teva, Pfizer, MSD, Aventis, Medtronic, Dexxon, Levant, Medisson, Neopharm, Novartis, and Schering-Plough.

\section{Publisher's Note}

Springer Nature remains neutral with regard to jurisdictional claims in published maps and institutional affiliations.

Received: 1 April 2017 Accepted: 29 July 2017

Published online: 14 August 2017

\section{References}

1. Levy D, Kenchaiah S, Larson MG, Benjamin EJ, Kupka MJ, Ho KK, Murabito $\mathrm{JM}$, Vasan RS. Long-term trends in the incidence of and survival with heart failure. NEngl J Med. 2002;347(18):1397-402.

2. Kannel WB, Hjortland M, Castelli WP. Role of diabetes in congestive heart failure: the Framingham study. Am J Cardiol. 1974;34(1):29-34.

3. Iribarren C, Karter AJ, Go AS, Ferrara A, Liu JY, Sidney S, Selby JV. Glycemic control and heart failure among adult patients with diabetes. Circulation. 2001:103(22):2668-73.

4. Gottdiener JS, Arnold AM, Aurigemma GP, Polak JF, Tracy RP, Kitzman DW, Gardin JM, Rutledge JE, Boineau RC. Predictors of congestive heart failure in the elderly: the cardiovascular health study. J Am Coll Cardiol. 2000;35(6):1628-37.

5. Bertoni AG, Hundley WG, Massing MW, Bonds DE, Burke GL, Goff DC Jr. Heart failure prevalence, incidence, and mortality in the elderly with diabetes. Diabetes Care. 2004:27(3):699-703.

6. Kristensen SL, Preiss D, Jhund PS, Squire I, Cardoso JS, Merkely B, Martinez F, Starling RC, Desai AS, Lefkowitz MP, et al. Risk related to pre-diabetes mellitus and diabetes mellitus in heart failure with reduced ejection fraction: insights from prospective comparison of ARNI With ACEI to determine impact on global mortality and morbidity in heart failure trial. Circ Heart Fail. 2016;9(1):e002560.

7. Sud M, Wang X, Austin PC, Lipscombe LL, Newton GE, Tu JV, Vasan RS, Lee DS. Presentation blood glucose and death, hospitalization, and future diabetes risk in patients with acute heart failure syndromes. Eur Heart J. 2015;36(15):924-31

8. Mebazaa A, Gayat E, Lassus J, Meas T, Mueller C, Maggioni A, Peacock F, Spinar J, Harjola VP, van Kimmenade R, et al. Association between elevated blood glucose and outcome in acute heart failure: results from an international observational cohort. J Am Coll Cardiol. 2013;61 (8):820-9.

9. Helfand BK, Maselli NJ, Lessard DM, Yarzebski J, Gore JM, McManus DD, Saczynski JS, Goldberg RJ. Elevated serum glucose levels and survival after acute heart failure: a population-based perspective. Diabetes Vasc Dis Res. 2015;12(2):119-25.

10. Barsheshet A, Garty M, Grossman E, Sandach A, Lewis BS, Gottlieb S, Sho$\tan$ A, Behar S, Caspi A, Schwartz R, et al. Admission blood glucose level and mortality among hospitalized nondiabetic patients with heart failure. Arch Intern Med. 2006;166(15):1613-9.

11. Kattel S, Kasai T, Matsumoto H, Yatsu S, Murata A, Kato T, Suda S, Hiki M, Takagi A, Daida H. Association between elevated blood glucose level on admission and long-term mortality in patients with acute decompensated heart failure. J Cardiol. 2017:69:619-24.

12. Targher G, Dauriz M, Laroche C, Temporelli PL, Hassanein M, Seferovic PM, Drozdz J, Ferrari R, Anker S, Coats A, et al. In-hospital and 1-year mortality associated with diabetes in patients with acute heart failure: results from the ESC-HFA heart failure long-term registry. Eur J Heart Fail. 2017;19:54-65

13. Newton JD, Squire IB. Glucose and haemoglobin in the assessment of prognosis after first hospitalisation for heart failure. Heart. 2006;92(10):1441-6.

14. Kosiborod M, Inzucchi SE, Spertus JA, Wang Y, Masoudi FA, Havranek EP, Krumholz HM. Elevated admission glucose and mortality in elderly patients hospitalized with heart failure. Circulation. 2009;119(14):1899-907. 
15. Novack V, Pencina M, Zahger D, Fuchs L, Nevzorov R, Jotkowitz A, Porath A. Routine laboratory results and 30 day and 1-year mortality risk following hospitalization with acute decompensated heart failure. PLoS ONE. 2010;5(8):e12184.

16. Berry C, Brett M, Stevenson K, McMurray JJ, Norrie J. Nature and prognostic importance of abnormal glucose tolerance and diabetes in acute heart failure. Heart. 2008;94(3):296-304.

17. Garty M, Shotan A, Gottlieb S, Mittelman M, Porath A, Lewis BS, Grossman E, Behar S, Leor J, Green MS, et al. The management, early and 1 year outcome in hospitalized patients with heart failure: a national Heart Failure Survey in Israel-HFSIS 2003. Isr Med Assoc J. 2007;9(4):227-33.

18. Remme WJ, Swedberg K. Comprehensive guidelines for the diagnosis and treatment of chronic heart failure. Task force for the diagnosis and treatment of chronic heart failure of the European Society of Cardiology. Eur J Heart Fail. 2002;4(1):11-22.

19. Kosiborod M, Rathore SS, Inzucchi SE, Masoudi FA, Wang Y, Havranek EP, Krumholz HM. Admission glucose and mortality in elderly patients hospitalized with acute myocardial infarction: implications for patients with and without recognized diabetes. Circulation. 2005;111(23):3078-86.

20. Lee DS, Austin PC, Rouleau JL, Liu PP, Naimark D, Tu JV. Predicting mortality among patients hospitalized for heart failure: derivation and validation of a clinical model. JAMA. 2003;290(19):2581-7.

21. Fonarow GC, Adams KF Jr, Abraham WT, Yancy CW, Boscardin WJ. Risk stratification for in-hospital mortality in acutely decompensated heart failure: classification and regression tree analysis. JAMA. 2005;293(5):572-80.

22. Nichols GA, Hillier TA, Erbey JR, Brown JB. Congestive heart failure in type 2 diabetes: prevalence, incidence, and risk factors. Diabetes Care. 2001;24(9):1614-9.

23. Zarich SW, Nesto RW. Diabetic cardiomyopathy. Am Heart J. 1989;118(5 Pt 1):1000-12.

24. Greenberg BH, Abraham WT, Albert NM, Chiswell K, Clare R, Stough WG, Gheorghiade M, O'Connor CM, Sun JL, Yancy CW, et al. Influence of diabetes on characteristics and outcomes in patients hospitalized with heart failure: a report from the organized program to initiate lifesaving treatment in hospitalized patients with heart failure (OPTIMIZE-HF). Am Heart J. 2007;154(2):277-8.

25. Boudina $S$, Abel ED. Diabetic cardiomyopathy revisited. Circulation. 2007;115(25):3213-23.

26. Kishi S, Gidding SS, Reis JP, Colangelo LA, Venkatesh BA, Armstrong AC, Isogawa A, Lewis CE, Wu C, Jacobs DR Jr, et al. Association of insulin resistance and glycemic metabolic abnormalities With LV structure and function in Middle Age: the CARDIA Study. JACC Cardiovasc Imaging. 2017;10(2):105-14.

27. Fontes-Carvalho R, Ladeiras-Lopes R, Bettencourt P, Leite-Moreira $A$ Azevedo A. Diastolic dysfunction in the diabetic continuum: association with insulin resistance, metabolic syndrome and type 2 diabetes. Cardiovasc Diabetol. 2015;14:4

28. Tenenbaum A, Motro M, Fisman EZ, Leor J, Freimark D, Boyko V, Mandelzweig L, Adler Y, Sherer Y, Behar S. Functional class in patients with heart failure is associated with the development of diabetes. Am J Med. 2003;114(4):271-5.

29. Demant MN, Gislason GH, Kober L, Vaag A, Torp-Pedersen C, Andersson C. Association of heart failure severity with risk of diabetes: a Danish nationwide cohort study. Diabetologia. 2014;57(8):1595-600.

30. Stranders I, Diamant M, van Gelder RE, Spruijt HJ, Twisk JW, Heine RJ, Visser FC. Admission blood glucose level as risk indicator of death after myocardial infarction in patients with and without diabetes mellitus. Arch Intern Med. 2004;164(9):982-8.

31. Norhammar AM, Ryden L, Malmberg K. Admission plasma glucose. Independent risk factor for long-term prognosis after myocardial infarction even in nondiabetic patients. Diabetes Care. 1999;22(11):1827-31.

32. Malmberg K, Norhammar A, Wedel H, Ryden L. Glycometabolic state at admission: important risk marker of mortality in conventionally treated patients with diabetes mellitus and acute myocardial infarction: longterm results from the diabetes and insulin-glucose infusion in acute myocardial infarction (DIGAMI) study. Circulation. 1999:99(20):2626-32.

33. Naito R, Miyauchi K, Ogita M, Kasai T, Kawaguchi Y, Tsuboi S, Konishi H, Okazaki S, Kurata T, Daida H. Impact of admission glycemia and glycosylated hemoglobin A1c on long-term clinical outcomes of non-diabetic patients with acute coronary syndrome. J Cardiol. 2014:63(2):106-11.

34. Woo E, Chan YW, Yu YL, Huang CY. Admission glucose level in relation to mortality and morbidity outcome in 252 stroke patients. Stroke J Cerebral Circ. 1988;19(2):185-91.

35. Williams LS, Rotich J, Qi R, Fineberg N, Espay A, Bruno A, Fineberg SE, Tierney WR. Effects of admission hyperglycemia on mortality and costs in acute ischemic stroke. Neurology. 2002;59(1):67-71.

36. Capes SE, Hunt D, Malmberg K, Pathak P, Gerstein HC. Stress hyperglycemia and prognosis of stroke in nondiabetic and diabetic patients: a systematic overview. Stroke J Cerebral Circ. 2001;32(10):2426-32.

37. Oswald GA, Smith CC, Betteridge DJ, Yudkin JS. Determinants and importance of stress hyperglycaemia in non-diabetic patients with myocardial infarction. Br Med J (Clin Res Ed). 1986;293(6552):917-22.

38. Eichhorn EJ, Bristow MR. Medical therapy can improve the biological properties of the chronically failing heart. A new era in the treatment of heart failure. Circulation. 1996;94(9):2285-96.

39. Benedict CR, Weiner DH, Johnstone DE, Bourassa MG, Ghali JK, Nicklas J, Kirlin P, Greenberg B, Quinones MA, Yusuf S. Comparative neurohormonal responses in patients with preserved and impaired left ventricular ejection fraction: results of the studies of left ventricular dysfunction (SOLVD) registry. The SOLVD investigators. J Am Coll Cardiol. 1993;22(4 Suppl A):146a-53a.

40. Rizza RA, Cryer PE, Haymond MW, Gerich JE. Adrenergic mechanisms for the effects of epinephrine on glucose production and clearance in man. Clin Investig. 1980;65(3):682-9.

41. Deibert DC, DeFronzo RA. Epinephrine-induced insulin resistance in man J Clin Investig. 1980;65(3):717-21.

42. Williams SB, Goldfine AB, Timimi FK, Ting HH, Roddy MA, Simonson DC, Creager MA. Acute hyperglycemia attenuates endothelium-dependent vasodilation in humans in vivo. Circulation. 1998;97(17):1695-701.

43. Title LM, Cummings PM, Giddens K, Nassar BA. Oral glucose loading acutely attenuates endothelium-dependent vasodilation in healthy adults without diabetes: an effect prevented by vitamins $C$ and $\mathrm{E}$. J Am Coll Cardiol. 2000;36(7):2185-91.

44. Rutter MK, Parise H, Benjamin EJ, Levy D, Larson MG, Meigs JB, Nesto RW, Wilson PW, Vasan RS. Impact of glucose intolerance and insulin resistance on cardiac structure and function: sex-related differences in the Framingham Heart Study. Circulation. 2003;107(3):448-54.

45. Cooper ME. Importance of advanced glycation end products in diabetesassociated cardiovascular and renal disease. Am J Hypertens. 2004;17(12 Pt 2):31s-8s.

46. Clark RJ, McDonough PM, Swanson E, Trost SU, Suzuki M, Fukuda M, Dillmann WH. Diabetes and the accompanying hyperglycemia impairs cardiomyocyte calcium cycling through increased nuclear O-GIcNAcylation. J Biol Chem. 2003;278(45):44230-7.

47. Candido R, Forbes JM, Thomas MC, Thallas V, Dean RG, Burns WC, Tikellis C, Ritchie RH, Twigg SM, Cooper ME, et al. A breaker of advanced glycation end products attenuates diabetes-induced myocardial structural changes. Circ Res. 2003;92(7):785-92.

48. Li J, Wu N, Dai W, Jiang L, Li Y, Li S, Wen Z. Association of serum calcium and heart failure with preserved ejection fraction in patients with type 2 diabetes. Cardiovasc Diabetol. 2016;15(1):140.

49. Oliver MF, Opie LH. Effects of glucose and fatty acids on myocardial ischaemia and arrhythmias. Lancet. 1994;343(8890):155-8.

50. Cavender MA, White WB, Jarolim P, Bakris GL, Cushman WC, Kupfer S, Gao Q, Mehta CR, Zannad F, Cannon CP et al. Serial measurement of high sensitivity troponin I and cardiovascular outcomes in patients with type 2 diabetes mellitus in the EXAMINE trial. Circulation. 2017.

51. Alonso N, Lupon J, Barallat J, de Antonio M, Domingo M, Zamora E, Moliner P, Galan A, Santesmases J, Pastor C, et al. Impact of diabetes on the predictive value of heart failure biomarkers. Cardiovasc Diabetol. 2016;15(1):151.

52. van den Berghe $G$, Wouters $P$, Weekers F, Verwaest $C$, Bruyninckx F, Schetz $M$, Vlasselaers D, Ferdinande $P$, Lauwers $P$, Bouillon R. Intensive insulin therapy in critically ill patients. NEngl J Med. 2001;345(19):1359-67.

53. Fath-Ordoubadi F, Beatt KJ. Glucose-insulin-potassium therapy for treatment of acute myocardial infarction: an overview of randomized placebo-controlled trials. Circulation. 1997;96(4):1152-6. 